\title{
Enhanced proliferation and differentiation of HO-1 gene-modified bone marrow-derived mesenchymal stem cells in the acute injured kidney
}

\author{
NANMEI LIU, HUILING WANG，GUOFENG HAN，JIN CHENG，WEIFENG HU and JINYUAN ZHANG
}

Department of Nephrology, The 455th Hospital of PLA, Shanghai 200052, P.R. China

Received September 6, 2016; Accepted February 20, 2018

DOI: $10.3892 /$ ijmm.2018.3670

\begin{abstract}
The aim of the present study was to investigate the effect of heme oxygenase-1 (HO-1) overexpression on the survival and differentiation ability of bone marrow-derived mesenchymal stem cells (BMSCs) in the acute kidney injury (AKI) microenvironment. HO-1-BMSCs and enhanced green fluorescent protein (eGFP)-BMSCs were constructed. Rat ischemia/reperfusion (I/R)-AKI-kidney homogenate supernatant was prepared to treat the BMSCs, eGFP-BMSCs and $\mathrm{HO}-1-\mathrm{BMSC}$ in vitro. In the AKI microenvironment, the HO-1-BMSCs exhibited a smaller proportion of cells at the G0/G1 phase, and a larger proportion of cells expressing proliferating cell nuclear antigen (PCNA) and cytokeratin 18 (CK18). Phosphorylated protein kinase B (Akt) and extracellular signal-regulated kinase (ERK) protein levels were observed to be increased in the HO-1-BMSCs compared with the BMSCs. LY294002 and PD98059 each inhibited the above effects. BMSCs, eGFP-BMSCs and HO-1-BMSCs were implanted into an I/R-AKI rat model. The proportions of $\mathrm{PCNA}^{+}$BMSCs and $\mathrm{CK} 18^{+} \mathrm{BMSCs}$ were higher in the HO-1-BMSCs group compared with the BMSCs group, which resulted in a decreased acute tubular necrosis score and improved renal function for the AKI rats. In conclusion, the enhanced proliferation and differentiation of HO-1-BMSCs suggest the beneficial effects of such cells in the BMSC-based therapy of AKI. The mechanism underlying these effects may involve the stimulation of Akt and ERK signaling.
\end{abstract}

\section{Introduction}

Acute kidney injury (AKI) is a common clinical disease with high morbidity and mortality rates (1-3). Despite fundamental advances in the understanding of AKI pathophysiology,

Correspondence to: Dr Nanmei Liu, Department of Nephrology, The 455th Hospital of PLA, 338 West Huaihai Road, Shanghai 200052, P.R. China

Email: nanmeiliu2016@163.com

Key words: bone marrow-derived mesenchymal stem cells, heme oxygenase-1, proliferation, differentiation, acute kidney injury definitive therapies remain limited. The utilization of bone marrow-derived mesenchymal stem cells (BMSCs) to treat AKI has increased in recent years. For example, studies have demonstrated that the infusion of BMSCs is able to protect against and accelerate recovery from AKI induced by cisplatinum (4), glycerol (5) and ischemia/reperfusion (I/R) (6-8).

However, the therapeutic efficacy of BMSCs is greatly limited by the poor survival of donor BMSCs in the ischemic kidney (9-12). Following transplantation into the ischemic kidney, BMSCs face a complex environment with numerous factors that can cause cell death, among which oxidative stress is the most adverse. Under normal conditions, the naturally-occurring antioxidant enzymes in the kidney counteract the adverse cellular effects of oxygen-containing free radicals. However, under AKI conditions, the protective ability of these scavengers is overwhelmed by the rapid generation of reactive oxygen species (ROS) (13). As a result, the increased levels of ROS induce the death of the transplanted BMSCs and reduce their differentiation potential (14-16).

Heme oxygenase-1 (HO-1), a stress-inducible rate-limiting enzyme, is sensitive to upregulation by a variety of stress mediators, including ischemia, hypoxia, oxidative stress and inflammatory cytokines (17). Studies have shown that HO-1 is an antioxidant enzyme, possessing cytoprotective activity in the ischemic environment (18), which enhances cell survival and activity $(19,20)$. Thus, it is also possible that HO-1 may prevent BMSCs from being injured by the AKI microenvironment. However, BMSCs themselves only secrete trace amounts of HO-1 (21), and only a little HO-1 is expressed in the renal medulla under the stress state because normal renal tissues express the HO-2 isoform (22). In addition, the stress-induced expression of HO-1 in the renal medulla is rate-limited and the generated HO-1 metabolizes quickly (23). Thus, the cytoprotective effect of the induced HO-1 is not able to balance the stress-induced injury to BMSCs or exert a positive effect. Therefore, obtaining the stable and efficient expression of HO-1 in BMSCs becomes a key issue that may be beneficial for BMSC transplantation in AKI.

In the present study, the expression of HO-1 in BMSCs was increased using a gene transfection technique. It was hypothesized that the HO-1 gene augmentation would improve the survival and differentiation of BMSCs under AKI conditions, and thereby potentially improve the effect of BMSC therapy on AKI. 


\section{Materials and methods}

Construction of HO-1-BMSCs and enhanced green fluorescent protein (eGFP)-BMSCs. Sprague-Dawley (SD) passage 3 BMSCs purchased from American Type Culture Collection (Manassas, VA, USA), were used for the preparation of infected cells, according to our previous study (24). Briefly, the target plasmids pLV.ExBi.P/Puro-EF1 $\alpha$-HO-1-IRES-eGFP and pLV.Ex 2 d.P/puro-EF1A>eGFP were successfully prepared using Gateway technology (25). The plasmids were co-transfected into 293FT cells (Shanghai Institute of Biochemistry and Cell Biology, Chinese Academy of Sciences, Shanghai, China) together with envelope helper plasmids (pLV/helper-SL3, pLV/helper-SL4 and pLV/helper-SL5; Guangzhou Saiye Biotechnology Co., Ltd., Guangzhou, China) to harvest lenti-HO-1-eGFP/puro (lenti-HO-1) or lenti-eGFP/puro (lenti-eGFP). The titers of lenti-HO-1 and lenti-eGFP were $1.7 \times 10^{8}$ and $6.5 \times 10^{8} \mathrm{TU} / \mathrm{ml}$, respectively.

BMSCs were plated in 6-well plates at a density of $2 \times 10^{5}$ cells/well. Following cell attachment, the BMSCs were infected with lenti-HO-1 or lenti-eGFP $(25 \mu \mathrm{l} /$ well $)$ and selected by $2.5 \mu \mathrm{l}$ puromycin $(1 \mu \mathrm{g} / \mathrm{ml})$. The infection efficacies of the BMSCs were evaluated using fluorescence microscopy. SD HO-1-BMSCs and SD eGFP-BMSCs were successfully prepared for further use.

Cell grouping. BMSCs, eGFP-BMSCs and HO-1-BMSCs resuspended in the medium were plated in 6-well plates with low-glucose Dulbecco's modified Eagle's medium (DMEM; Gibco; Thermo Fisher Scientific, Shanghai, China) at the density of $4 \times 10^{5}$ cells/well. A Transwell chamber with a $0.4-\mu \mathrm{m}$ pore-sized polycarbonate filter (Corning Incorporated, Corning, NY, USA) was introduced in order to add the interventions. The Transwell chambers were plugged into the plates and AKI-kidney homogenate supernatant AKI-(KHS) or normal-KHS (N-KHS) was added to the upper chambers. The protocols for the preparation of AKI-KHS and N-KHS were as previously described (24). Briefly, models of I/R-AKI were created using 6-8-week-old SD rats weighing 150-200 g; (Experimental Animal Center of the Second Military Medical University, Shanghai, China; animal production license, no. SCXK 2007-0003) by clamping the two renal pedicles for $45 \mathrm{~min}$ followed by clamp-release to allow reperfusion. At 45 min following the initiation of reperfusion, bilateral kidneys were excised and the corticomedullary junction of the kidneys was obtained and used to prepare a $20 \mathrm{~g} / \mathrm{l}$ homogenate. The homogenate was then centrifuged and the supernatant was filtered with a 30- $\mu$ m-mesh disposable sterile filter to obtain the AKI-KHS. This AKI-KHS was used to generate AKI in vitro. The N-KHS from control healthy SD rats was used as the control. Ethical approval for the animal experiments conducted in the present study was provided by the Animal Experimentation Institution of the Second Military University (Shanghai, China).

Five groups were established: Blank group (BMSCs group; $1.5 \mathrm{ml}$ low-glucose DMEM was added to the upper chamber), control group (BMSCs/N-KHS group; $1.5 \mathrm{ml} \mathrm{N-KHS} \mathrm{was}$ added to the upper chamber), BMSCs/AKI-KHS group, eGFP-BMSCs/AKI-KHS group and HO-1-BMSCs/AKI-KHS group. For the last three groups, $1.5 \mathrm{ml}$ AKI-KHS was added to the upper chamber. All the groups were incubated at $37^{\circ} \mathrm{C}$ for 3 days in humidified atmosphere with $5 \% \mathrm{CO}_{2}$.

Cell cycle profiles. Cells were trysinized and harvested by centrifugation at $167.7 \mathrm{x} \mathrm{g}$ at $4^{\circ} \mathrm{C}$ for $10 \mathrm{~min}$. The cell pellets were incubated in $10 \mu \mathrm{l}$ propidium iodide $(50 \mu \mathrm{g} / \mathrm{ml})$ at room temperature for $30 \mathrm{~min}$. The proportions of cells in the G0/G1, $\mathrm{S}$ and $\mathrm{G} 2$ phases were analyzed by flow cytometry using BD CellQuest software (version 341753 rev.A; BD Biosciences, San Jose, CA, USA) with an excitation at $488 \mathrm{~nm}$ according to the manufacturer's instructions.

Immunohistochemical staining of proliferating cell nuclear antigen (PCNA). PCNA, a marker of mitogenesis (26), was detected using immunohistochemical staining. The cells were fixed in $4 \%$ paraformaldehyde for $30 \mathrm{~min}$ at room temperature. Sections were incubated with rabbit anti-rat PCNA polyclonal antibody (A0264; dilution 1:2,000; ABclonal, Woburn, MA, USA) at $4^{\circ} \mathrm{C}$ for $16 \mathrm{~h}$, and then incubated with horseradish peroxidase (HRP)-conjugated goat anti-rabbit secondary antibody (PAB29760; dilution 1:2,000; Abnova, Walnut, CA, USA) at $37^{\circ} \mathrm{C}$ for $1 \mathrm{~h}$. Non-overlapping view fields $(n=15$; x200 magnification) were selected and the mean value of the proportion of $\mathrm{PCNA}^{+}$cells for each section was used for statistical analysis.

Cell ultrastructure. Cells were trysinized and harvested by centrifugation at $168 \mathrm{x} \mathrm{g}$ at $4^{\circ} \mathrm{C}$ for $5 \mathrm{~min}$. The cell pellets were rinsed with $0.1 \mathrm{M}$ phosphate buffer and then fixed with $1 \%$ osmic acid for $1 \mathrm{~h}$ at $4^{\circ} \mathrm{C}$. Following a further rinse, the pellets were dehydrated using a graded acetone series and embedded in Araldite resin. Ultrathin sections (50-70 nm) were double-stained with uranyl acetate at room temperature for $15 \mathrm{~min}$ and lead citrate and subjected to ultrastructural evaluation using the Hitachi H-7500 transmission electron microscope (TEM; Hitachi, Ltd., Tokyo, Japan).

Renal epithelial-differentiation of the BMSCs. Immunohistochemical staining was performed to detect whether BMSCs expressed cytokeratin 18 (CK18). The protocol was as described above for PCNA, with the exception that goat anti-rat CK18 polyclonal antibody (ABP50186; dilution 1:2,000; ABclonal) was used as the primary antibody.

Quantification of signaling protein phosphorylation in the BMSCs. The phosphorylation of the signaling proteins protein kinase B (Akt) and extracellular signal-regulated kinase (ERK) were assayed by western blot analysis. BCA was used to determine the protein concentration. Briefly, a $0.1-\mathrm{ml}$ pipette of each standard and unknown protein sample was replicated into an appropriately labeled test tube. Two blank tubes were set in duplicate. For a standard curve, $0.1 \mathrm{ml} \mathrm{H}_{2} \mathrm{O}$ was added instead of BSA solution. For the protein samples, $0.1 \mathrm{ml}$ protein preparation buffer was added. Subsequently, $2.0 \mathrm{ml} \mathrm{WR}$ were added to each tube and mixed well. The tubes were then covered and incubated at $37^{\circ} \mathrm{C}$ for $30 \mathrm{~min}$. All tubes were kept at room temperature for $10 \mathrm{~min}$ before measurement. Finally, absorbance readings were taken at $562 \mathrm{~nm}$. The BMSCs, eGFP-BMSCs and HO-1-BMSCs were scraped in radioimmunoprecipitation assay buffer (Gibco; Thermo Fisher Scientific) including protease inhibitors. Following separation 
by sodium dodecyl sulfate-polyacrylamide gel electrophoresis (5\% concentrated and $10 \%$ separation), the proteins $(10 \mu \mathrm{l}$ per lane) were transferred to a polyvinylidene difluoride (PVDF) membrane and blocked with Tris-buffered saline and Tween 20 containing $1 \%$ bovine serum albumin (Gibco; Thermo Fisher Scientific) at room temperature for $4 \mathrm{~h}$. The PVDF membrane was incubated with rabbit anti-rat phospho-Akt (pAkt) monoclonal antibody (4060s; dilution 1:2,000) and rabbit anti-rat phospho-ERK (pERK; 5683s; dilution 1:2,000) monoclonal antibody (both from Cell Signaling Technology, Inc., Danvers, MA, USA) at $4^{\circ} \mathrm{C}$ overnight. HRP-labeled goat anti-rabbit IgG (Santa Cruz Biotechnology, Inc., Dallas, TX, USA) was added and the membrane was incubated for $1 \mathrm{~h}$ at room temperature. Following 1-2 min incubation with ECL reagent (Shanghai Ruisai Biotechnology Co., Ltd., Shanghai, China), the PVDF membrane was placed into a FluorChem HD2 gel image analysis system (ProteinSimple, San Jose, CA, USA) for observation of the protein blots. $\beta$-actin was used as the internal reference and protein expression was calculated as the ratio of the band intensity of the protein of interest to that of $\beta$-actin.

Phosphatidylinositol 3-kinase (PI3K)/Akt and mitogen-activated protein kinase (MEK)/ERK inhibition studies. In these experiments, the PI3K/Akt inhibitor LY294002 or the MEK inhibitor PD98059 (both from Sigma-Aldrich; Merck KGaA, Darmstadt, Germany) were applied at a concentration of $5 \mu \mathrm{M}$. The HO-1-BMSCs were pre-incubated with LY294002 or PD98059 for $1 \mathrm{~h}$, and then cultured under the aforementioned AKI-KHS treatment conditions for 3 days. The cell cycle profile, proportion of $\mathrm{PCNA}^{+} \mathrm{HO}-1-\mathrm{BMSC}$ and proportion of $\mathrm{CK} 18^{+} \mathrm{HO}-1-\mathrm{BMSC}$ were detected as already described.

Induction of I/R-AKI and BMSC implantation in vivo. Rat models of I/R-AKI were prepared using the protocols described in Cell grouping. At the time of reperfusion, BMSCs $\left(2 \times 10^{6}\right.$ cells suspended in $0.2 \mathrm{ml}$ low-glucose DMEM) were injected into the renal artery. Prior to implantation, the BMSCs, eGFP-BMSCs and HO-1-BMSCs were labeled with 4',6-diamidino-2-phenylindole (DAPI; Sigma-Aldrich; Merck KGaA). The labeling efficiencies were all $>98 \%$ without significant differences.

The rats were randomly assigned to five experimental groups ( $\mathrm{n}=10$ for each group) as follows: Control group (the kidneys of the SD rats were exposed for $45 \mathrm{~min}$, and then $0.2 \mathrm{ml}$ low-glucose DMEM was injected into the renal artery), model group (the I/R-AKI group; $0.2 \mathrm{ml}$ low-glucose DMEM was injected into the renal artery at the time of reperfusion), and BMSCs, eGFP-BMSCs and HO-1-BMSCs groups. All rats were kept at a temperature of $24^{\circ} \mathrm{C}$ and $50 \%$ humidity with an unlimited supply of water and food and were housed under a normal $12 \mathrm{~h}$ light- $12 \mathrm{~h}$ dark cycle. At 3 days following the injection of BMSCs, the rats were humanely euthanized and transcardially-flushed with phosphate-buffered saline (PBS). The excised kidneys were flushed with PBS again, and were fixed in $4 \%$ paraformaldehyde for further use. All procedures were performed in accordance with the principles of the Guidelines for Animal Experimentation of The Second Military Medical University.

Acute tubular necrosis (ATN) score. Kidneys were fixed in $10 \%$ phosphate-buffered formalin, sectioned, and stained with periodic acid-Schiff (PAS) by standard methods (27). A renal pathologist conducted a histological examination in a blinded manner. The ATN score was quantified by counting the percentage of tubules that displayed cell necrosis, brush border loss, naked basement membrane and vacuolar degeneration as follows: 0 , none; $1, \leq 10 \% ; 2,11-25 \% ; 3,26-45 \%$; $4,46-75 \%$ and $5, \geq 76 \%$.

Proliferation and differentiation of BMSCs in the injured kidney in vivo. $\mathrm{PCNA}^{+} \mathrm{BMSCs}$ in the kidney were detected using immunofluorescent staining. Briefly, following deparaffination, the kidney sections $(1.5-\mu \mathrm{m}$ thick) were dehydrated with graded ethanol and incubated with a peroxidase-blocking reagent (5\% BSA; Thermo Fisher Scientific) for $30 \mathrm{~min}$ at room temperature. The sections were incubated with rabbit anti-rat PCNA polyclonal antibody (A0264; dilution 1:2,000; ABclonal) at $4^{\circ} \mathrm{C}$ overnight. After being washed with PBS, the sections were incubated with TRITC-conjugated antirabbit antibody (6909-250; dilution 1:1,000; BioVision, Milpitas, CA, USA) at $37^{\circ} \mathrm{C}$ for $1.5 \mathrm{~h}$. The treatment with the TRITC-conjugated antibody was followed by DAPI counterstaining at room temperature for $5 \mathrm{~min}$. $\mathrm{PCNA}^{+}$nuclei appeared red, $\mathrm{DAPI}^{+}$nuclei appeared blue and the nuclei of $\mathrm{PCNA}^{+} \mathrm{DAPI}^{+}$cells $\left(\mathrm{PCNA}^{+} \mathrm{BMSCs}\right)$ appeared purple. The proportion of $\mathrm{PCNA}^{+} \mathrm{BMSC}$ was calculated as the following ratio: Number of $\mathrm{PCNA}^{+} \mathrm{DAPI}^{+}$cells / number of $\mathrm{DAPI}^{+}$cells.

Immunofluorescent staining was also performed to detect whether the BMSCs trapped in the kidney expressed CK18. The protocol was conducted as described for PCNA, using goat anti-rat CK18 polyclonal antibody (ABP50186; dilution 1:2,000; ABclonal) as the primary antibody. $\mathrm{CK}_{18}{ }^{+} \mathrm{DAPI}^{+}$cells $\left(\mathrm{CK} 18^{+} \mathrm{BMSCs}\right)$ were those having blue nuclei with red cytoplasm. The results were expressed as the following ratio: Number of $\mathrm{CK} 18^{+} \mathrm{DAPI}^{+}$cells / number of $\mathrm{DAPI}^{+}$cells.

Statistical analysis. Results are expressed as the mean \pm standard deviation. Student's t-tests were performed to analyze the differences between two groups. Multiple-group comparisons were performed using one-way analysis of variance followed by Student-Newman-Keuls tests. SPSS 19.0 statistical software (IBM Corp., Armonk, NY, USA) was used for the analysis. $\mathrm{P}<0.05$ was considered to indicate a statistically significant difference.

\section{Results}

HO-1 overexpression improves the survival of BMSCs in the AKI microenvironment. BMSCs were indirectly cultured with AKI-KHS to simulate implanted BMSCs trapped in the AKI kidney in vivo. Flow cytometric analysis demonstrated that the N-KHS intervention had no effect on the cell cycle profile of the cultured BMSCs when compared with the blank group. However, compared with the control group, the AKI-KHS intervention inhibited the normal mitosis of the cultured BMSCs and induced cell-cycle arrest at the G0/G1 phase. The proportion of cells in the G0/G1 phase was increased significantly in the BMSCs/AKI-KHS group $(\mathrm{P}<0.05$ vs. control group; Fig. $1 \mathrm{~A}$ and $\mathrm{B})$. As a result, there appeared to be fewer BMSCs in the G2 phase, and PCNA 
A

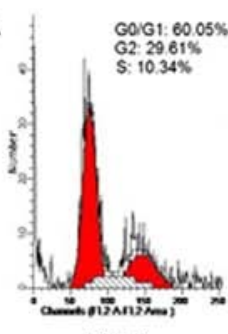

Blank

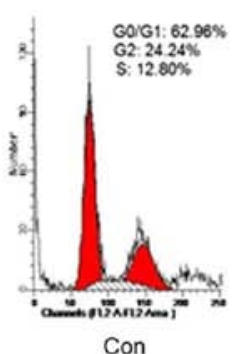

Con

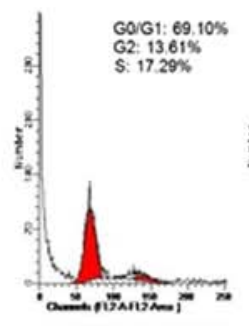

BMSCS/AKI-KHS

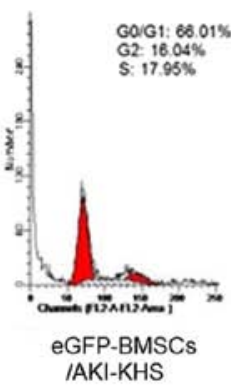

IAKI-KHS

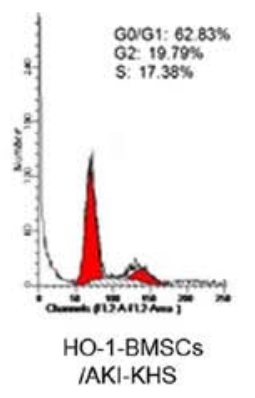

B

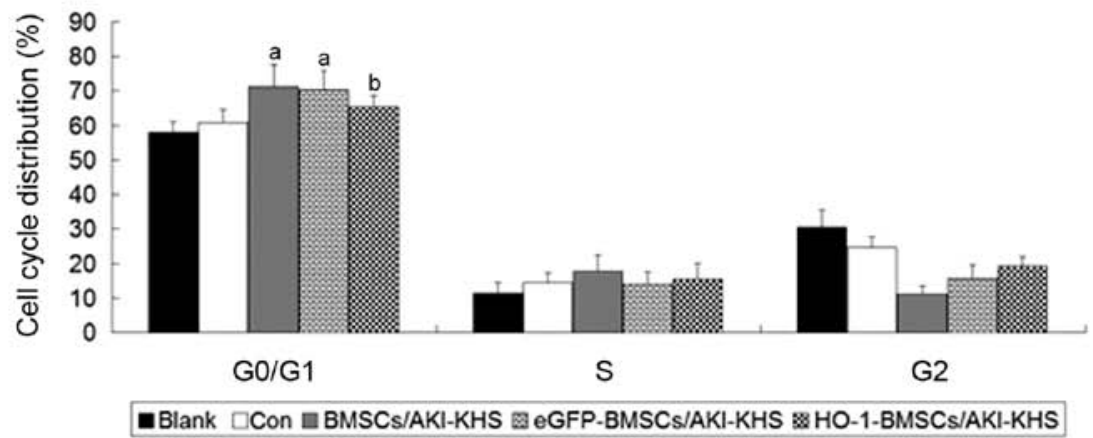

C

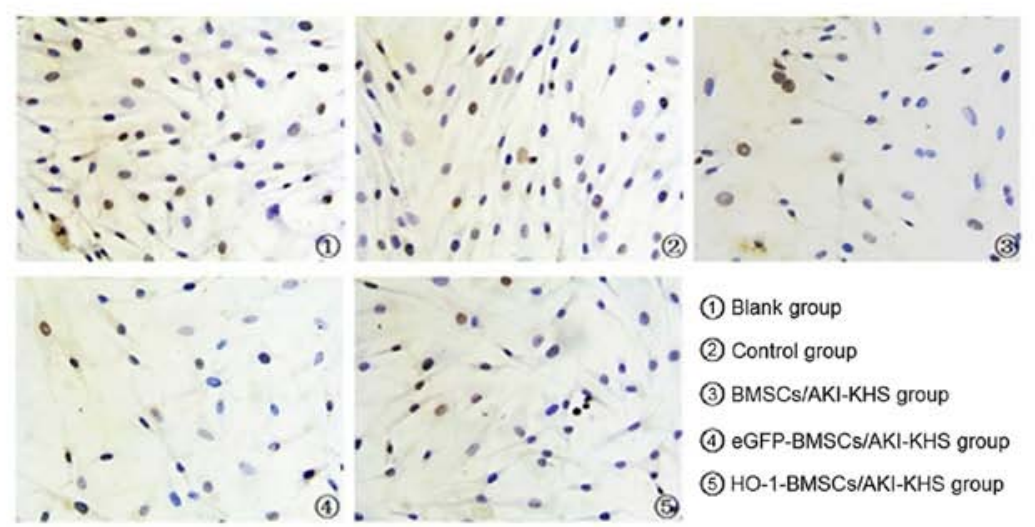

D

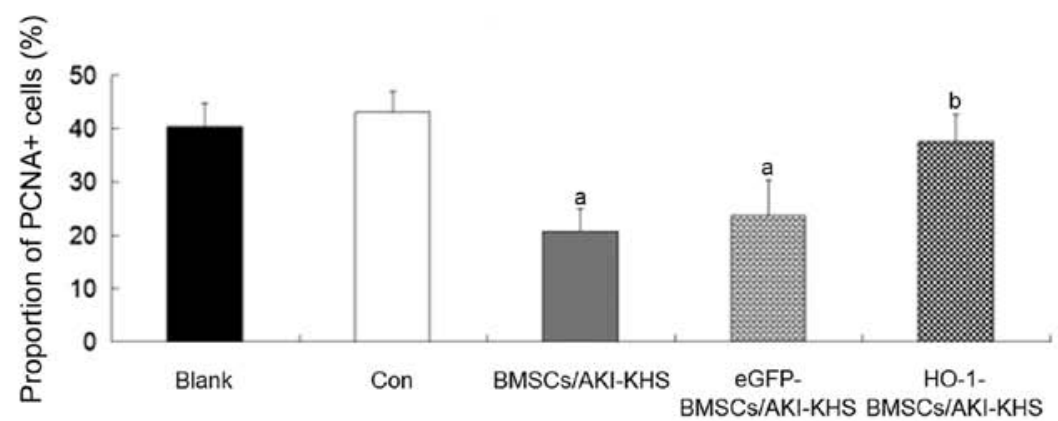

Figure 1. Protective effect of HO-1 overexpression on BMSC survival. BMSCs indirectly cultured with AKI- KHS were used to simulate implanted BMSCs trapped in the AKI in vivo. (A) Cell cycle profiles. (B) Quantitative analysis of the cell cycle profile. The cell cycle of BMSCs induced by AKI-KHS arrested at the G0/G1 phase. However, the expression of HO-1 decreased the proportion of BMSCs at the G0/G1 phase. (C) Immunohistochemical staining of PCNA in BMSCs (x200 magnification). Brown nuclei indicated PCNA ${ }^{+}$cells. (D) Quantitative analysis of the PCNA expression. The proportion of the PCNA ${ }^{+}$cells in the HO-1-BMSCs/AKI-KHS group was increased significantly compared with the BMSCs/AKI-KHS group. Results are presented as the mean \pm standard deviation ( $\mathrm{n}=6$ ). ${ }^{a} \mathrm{P}<0.05$ vs. control group; ${ }^{\mathrm{b}} \mathrm{P}<0.05$ vs. BMSCs/AKI-KHS group. HO-1, heme oxygenase-1; BMSC, bone marrow-derived mesenchymal stem cell; AKI, acute kidney injury; KHS, kidney homogenate supernatant; PCNA, proliferating cell nuclear antigen; blank, blank group (BMSCs with medium); con, control group (BMSCs with normal KHS); eGFP, enhanced green fluorescent protein.

expression was significantly decreased $(\mathrm{P}<0.05$ vs. control group; Fig. 1C and D). No significant differences were detected between the BMSCs/AKI-KHS group and the eGFPBMSCs/AKI-KHS group. However, HO-1 gene modification significantly attenuated the cell-cycle arrest, decreased the proportion of cells in the G0/G1 phase, and increased the proportion of $\mathrm{PCNA}^{+}$cells $(\mathrm{P}<0.05$ vs. BMSCs/AKI-KHS group). Notably, the proportion of $\mathrm{PCNA}^{+}$cells in the HO-1-BMSCs/AKI-KHS group was similar to those of the blank and control groups (Fig. 1C and D). 
A

B

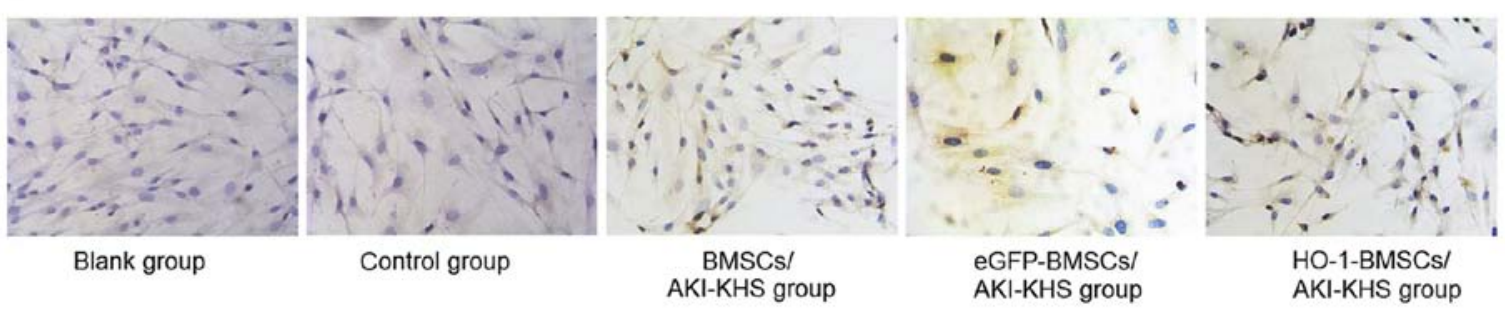

C

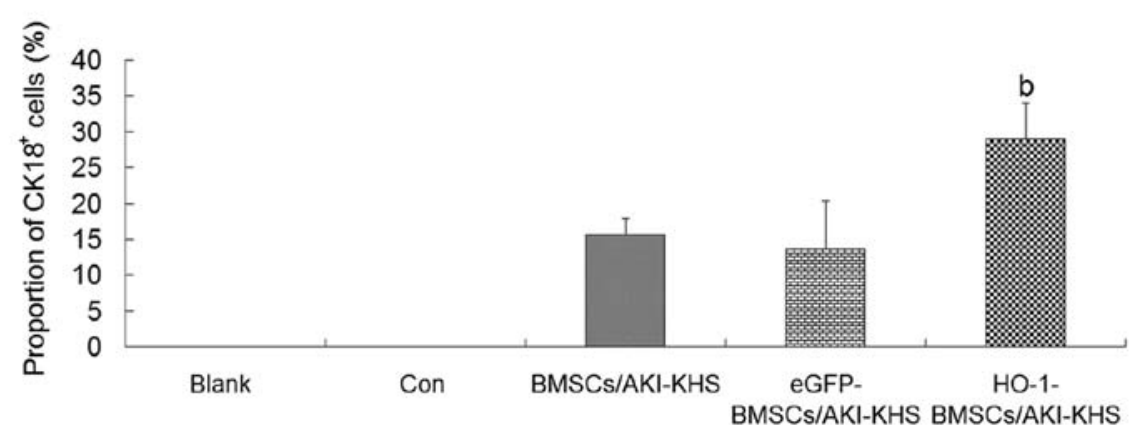

Figure 2. Renal-epithelial differentiation of BMSCs in vitro. (A) Transmission electron microscopy images of BMSCs treated with different KHSs. BMSCs of the blank and control groups were characterized by large nuclei with few organelles in the cytoplasm. AKI-KHS induced the renal-epithelial differentiation of BMSCs. Greater numbers of cytoplasm organelles and some epithelial-specific structures (the intercellular junction and the microvilli) emerged in the BMSCs. Scale bar, $2 \mu \mathrm{m}$. The red numbers indicate the following features: 1 , lysosomes; 2 , granular endoplasmic reticulum; 3 , intercellular junction; and 4 , microvilli. (B) Immunohistochemical staining of CK18 in BMSCs (magnification, x200). Cells with brown cytoplasm represented CK18 ${ }^{+}$cells. (C) Quantitative analysis of the proportion of $\mathrm{CK} 18^{+}$cells. The HO-1-BMSCs/AKI-KHS group exhibited a significant increase in the proportion of CK18 ${ }^{+}$cells. Results are presented as the mean \pm standard deviation $(n=6) .{ }^{b} \mathrm{P}<0.05$ vs. BMSCs/AKI-KHS group. BMSCs, bone marrow-derived mesenchymal stem cells; KHS, kidney homogenate supernatant; AKI, acute kidney injury; CK18, cytokeratin 18; HO-1, heme oxygenase-1; blank, blank group (BMSCs with medium); con, control group (BMSCs with normal-KHS); eGFP, eGFP, enhanced green fluorescent protein.

Cell ultrastructure. Under the TEM, the BMSCs of the blank and control groups were characterized by large nuclei and few organelles. AKI-KHS induced epithelial differentiation of the BMSCs. Increased quantities of granular endoplasmic reticulum, lysosomes and mitochondria were visible in the cytoplasm of the BMSCs in the BMSCs/AKI-KHS group (Fig. 2A). In addition, microvilli and intercellular junctions, which are specific to epithelial cells, were observed on the surface of the BMSCs (Fig. 2A). These changes are indicative of the differentiation of the cultured BMSCs. These ultrastructural changes were also observed in the cells of the eGFP-BMSCs/AKI-KHS group and the HO-1-BMSCs/AKI-KHS group when observed using TEM (data not shown).

Renal-epithelial differentiation of BMSCs in vitro. To test whether HO-1 overexpression had a positive effect on the renalepithelial differentiation of BMSCs, the expression of CK18, a specific marker of renal tubular epithelial cells (RTECs) $(28,29)$, was examined. Cells with brown cytoplasm represented the CK $18^{+}$BMSCs (Fig. 2B). The immunohistochemical staining results demonstrated that the AKI microenvironment induced the expression of CK18 in BMSCs, and HO-1 overexpression enhanced this capacity. The proportion of $\mathrm{CK} 18^{+}$cells in the HO-1BMSCs/AKI-KHS group was significantly higher compared with that in the BMSCs/AKI-KHS group $(\mathrm{P}<0.05$; Fig. $2 \mathrm{C})$.

PI3K/Akt and MEK/ERK signal pathways are involved in the enhanced survival and differentiation of HO-1-BMSCs. Previous studies demonstrated that the PI3K/Akt and MEK/ERK pathways are two important signaling pathways involved in BMSC survival (30). The phosphorylation of Akt and ERK is also reported to be involved in the osteogenic differentiation of mesenchymal stem cells $(31,32)$. In the present study, to explore the signaling pathways of the cytoprotective effect of HO-1 overexpression on BMSCs, the intracellular phosphorylation levels of Akt and ERK were examined. The levels of pAkt and pERK were significantly decreased in the BMSCs and eGFP-BMSCs treated with AKI-KHS compared with the control group $(\mathrm{P}<0.05)$; however, the levels of these proteins were increased significantly in the HO-1-BMSCs compared with the BMSCs/AKI-KHS ( $<<0.05$; Fig. 3). These results suggest that the cytoprotective effect of HO-1 

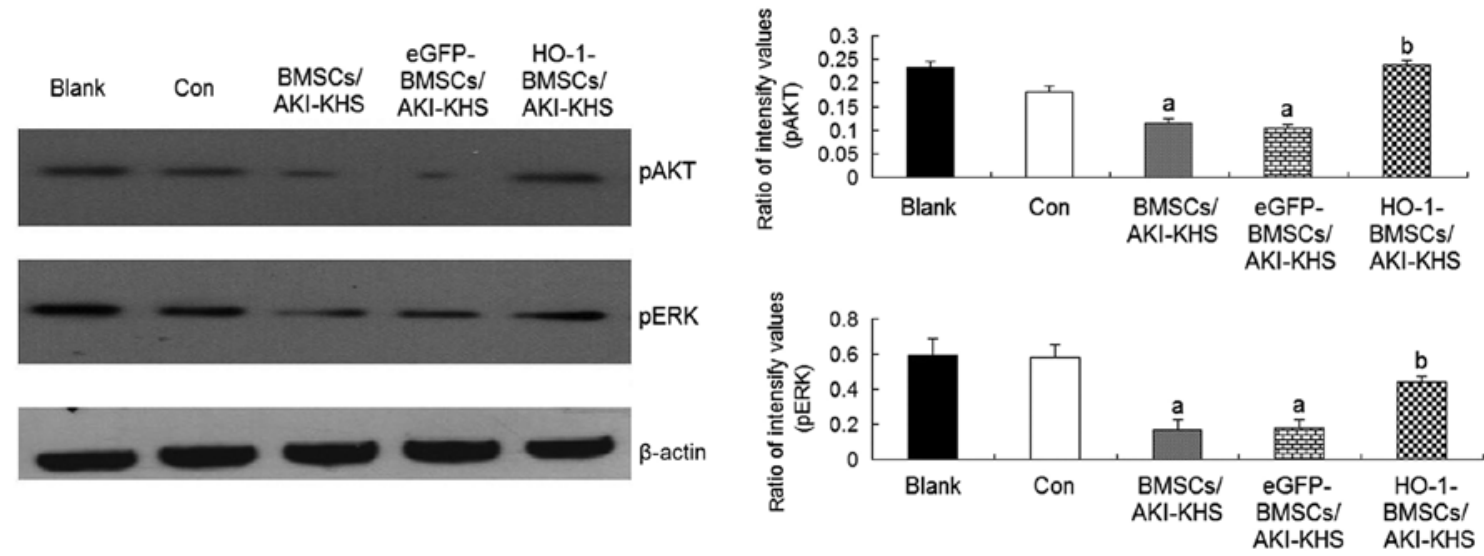

Figure 3. Phosphorylation of Akt and ERK in BMSCs. HO-1 gene modification increased the phosphorylation of Akt and ERK in BMSCs in the AKI microenvironment. Results are presented as the mean \pm standard deviation $(n=6)$. ${ }^{a} \mathrm{P}<0.05$ vs. control group; ${ }^{~} \mathrm{P}<0.05$ vs. BMSCs/AKI-KHS group. ERK, extracellular signal-regulated kinase; pERK, phosphorylated ERK; Akt, protein kinase B; pAkt, phosphorylated Akt; BMSCs, bone marrow-derived mesenchymal stem cells; HO-1, heme oxygenase-1; AKI, acute kidney injury; KHS, kidney homogenate supernatant; blank, blank group (BMSCs with medium); con, control group (BMSCs with normal-KHS); eGFP, enhanced green fluorescent protein.

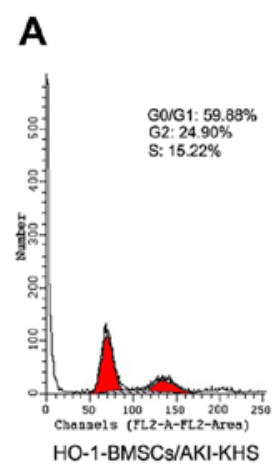

B

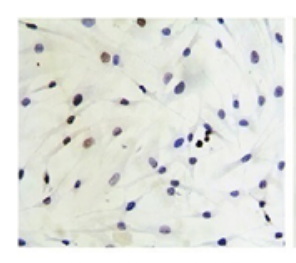

HO-1-BMSCS/AKI-KHS

C
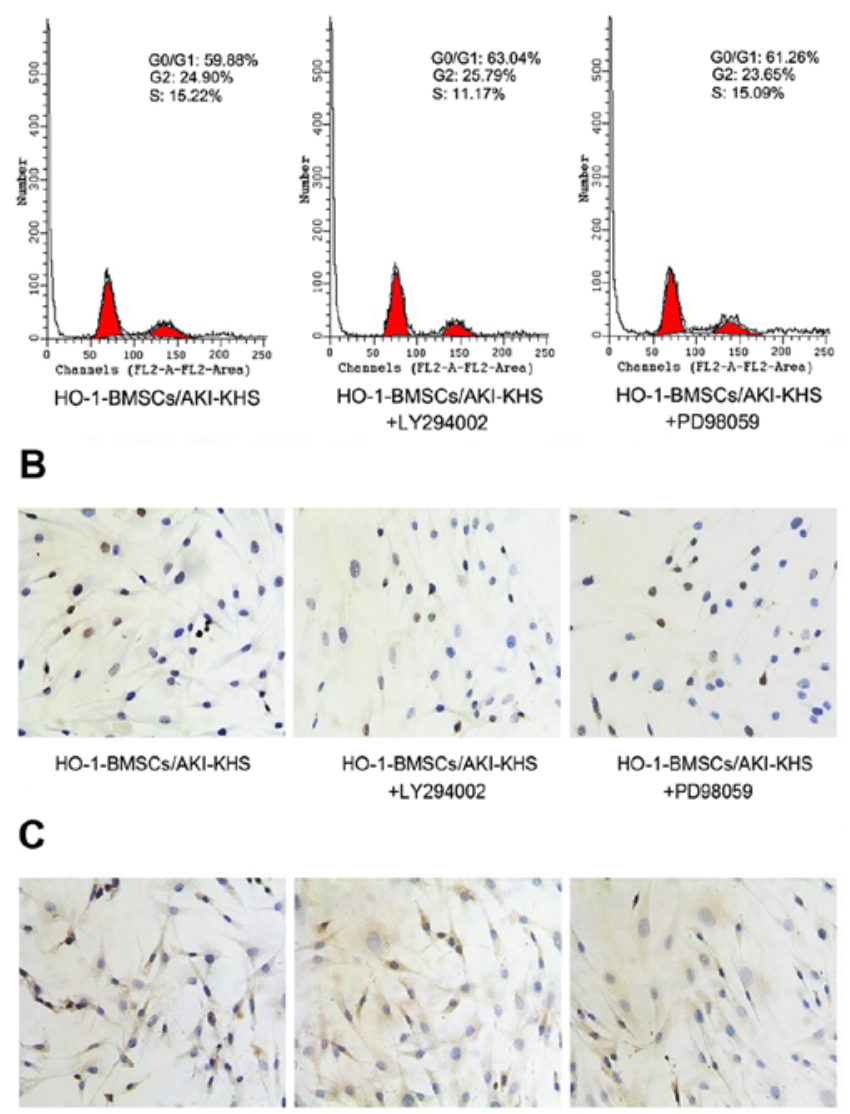

HO-1-BMSCs/AKI-KHS

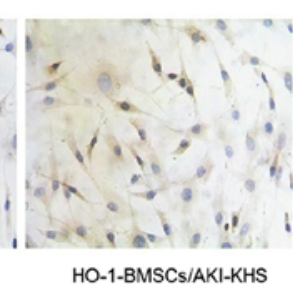

+ LYY294002

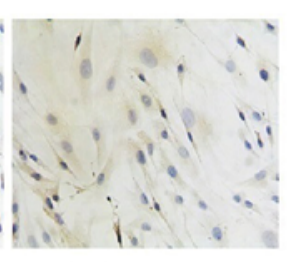

HO-1-BMSCs/AKI-KHS + PD98059
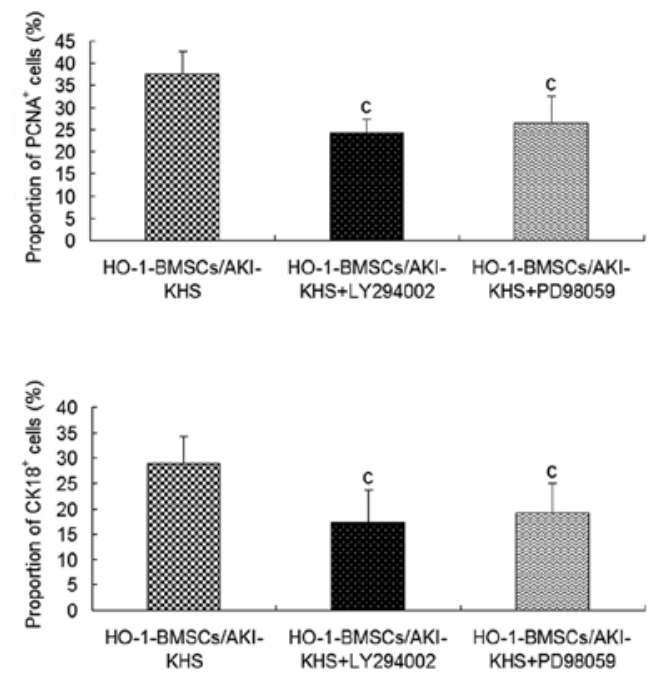

Figure 4. Inhibition of the PI3K/Akt and MEK/ERK pathways by the PI3K inhibitor LY294002 and MEK inhibitor PD98059. Pre-incubation with LY294002 or PD98059 attenuated the cytoprotective effect of HO-1 overexpression on BMSCs. (A) No significant differences in cell cycle profiles was observed among the three groups. LY294002 and PD98059 significantly decreased the expression of (B) PCNA and (C) CK18 in the HO-1-BMSCs (x200 magnification). Results are presented as mean \pm standard deviation $(\mathrm{n}=6)$. ${ }^{\mathrm{C}} \mathrm{P}<0.05$ vs. HO-1-BMSCs/AKI-KHS group. PI3K, phosphatidylinositol 3-kinase; Akt, protein kinase B; MEK, mitogen-activated protein kinase; ERK, extracellular signal-regulated kinase; HO-1, heme oxygenase-1; BMSCs, bone marrow-derived mesenchymal stem cells; PCNA, proliferating cell nuclear antigen; CK18, cytokeratin 18; AKI, acute kidney injury; KHS, kidney homogenate supernatant; blank, blank group (BMSCs with medium); con, control group (BMSCs with normal-KHS); eGFP, enhanced green fluorescent protein.

overexpression may involve the PI3K/Akt and MEK/ERK signaling pathways.
Effects of PI3K/Akt and MEK/ERK inhibition of HO-1-BMSCs. To further explore whether the PI3K/Akt and MEK/ERK 
A
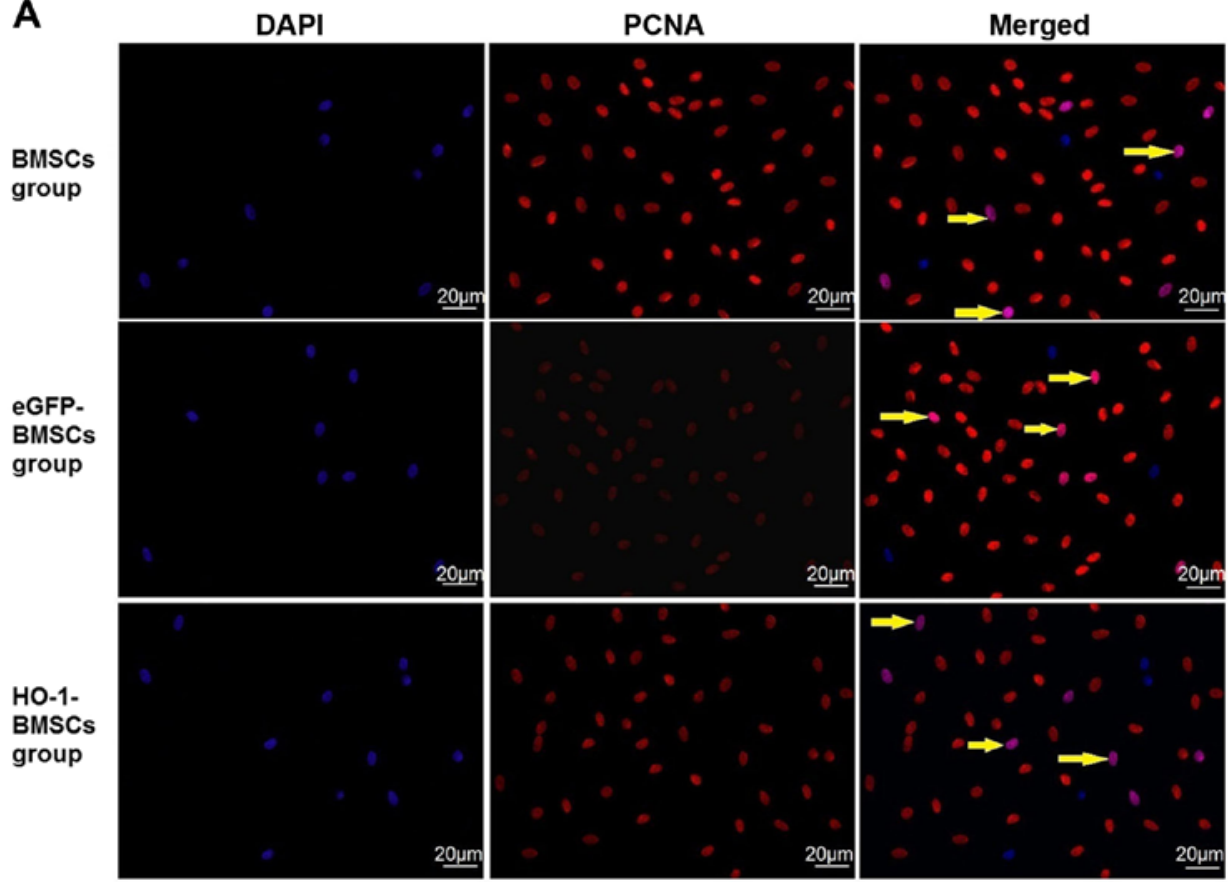

B

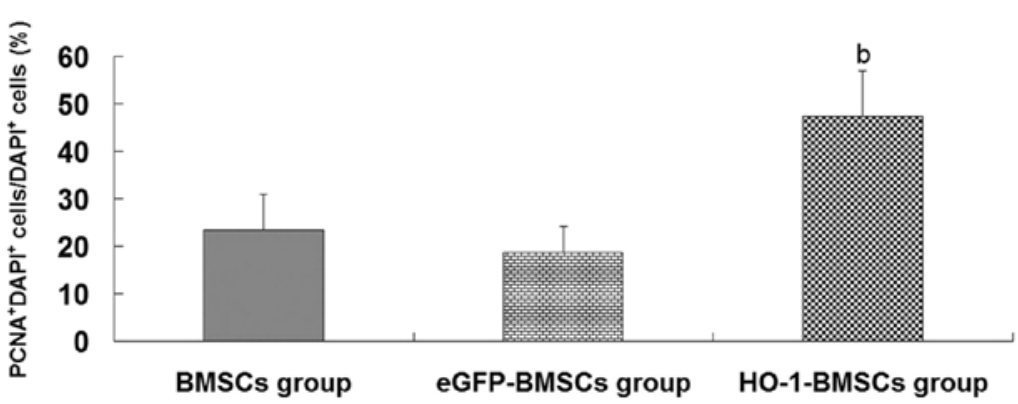

Figure 5. PCNA ${ }^{+}$BMSCs trapped in the kidneys of rats with ischemia/reperfusion-induced acute kidney injury. (A) Immunofluorescent staining images. Blue nuclei in the left panel indicate $\mathrm{DAPI}^{+}$cells (BMSCs), red nuclei in the middle panel indicate PCNA ${ }^{+}$cells, and purple nuclei (arrows) in the right panel indicate $\mathrm{PCNA}^{+} \mathrm{DAPI}^{+}$cells (PCNA ${ }^{+} \mathrm{BMSCs}$ ). Scale bar, $20 \mu \mathrm{m}$. (B) Quantitative analysis. The ratio of PCNA ${ }^{+} \mathrm{BMSCs}_{\mathrm{BMSC}}$ in the HO-1-BMSCs group is the highest. Results are presented as the mean \pm standard deviation ( $\mathrm{n}=10$ rats). ${ }^{\mathrm{b}} \mathrm{P}<0.05$ vs. BMSCs group. PCNA, proliferating cell nuclear antigen; BMSCs, bone marrow-derived mesenchymal stem cells; HO-1, heme oxygenase-1; eGFP, enhanced green fluorescent protein.

signaling pathways are involved in the improved survival and differentiation of HO-1-BMSCs in the AKI microenvironment, LY294002 and PD98059 were used to block PI3K/Akt and MEK/ERK activities respectively. The cell cycle profile of the HO-1-BMSCs in the presence of LY294002 or PD98059 exhibited no significant difference from that of the HO-1BMSCs/AKI-KHS group (Fig. 4A). However, as shown in Fig. 4B and C, significantly decreased proportions of $\mathrm{PCNA}^{+}$and $\mathrm{CK} 18^{+}$cells were detected for the HO-1-BMSCs in the presence of LY294002 or PD98059 (P<0.05 vs. the HO-1-BMSCs/AKI-KHS group).

Proliferation and renal-epithelial differentiation of implanting BMSCs in the injured kidney in vivo. BMSCs, eGFP-BMSCs and HO-1-BMSCs were labeled with DAPI. Three days following their injection into the renal artery, the trapped $\mathrm{DAPI}^{+} \mathrm{BMSCs}$ in the injured kidney were assessed by PCNA assay. Cells with red nuclei were $\mathrm{PCNA}^{+}$cells and cells with purple nuclei were $\mathrm{PCNA}^{+} \mathrm{DAPI}^{+}$cells $\left(\mathrm{PCNA}^{+} \mathrm{BMSCs}\right)$. No difference was observed in the proportions of $\mathrm{PCNA}^{+}$ BMSCs between the BMSCs group and the eGFP-BMSCs group (Fig. 5). However, in the HO-1-BMSCs group, the proportion of $\mathrm{HO}-1-\mathrm{BMSC}$ that were positive for PCNA expression was significantly increased $(\mathrm{P}<0.05$ vs. BMSCs group; Fig. 5).

In the renal-epithelial differentiation assay, cells with red fluorescence in the cytoplasm were $\mathrm{CK} 18^{+}$cells. The immunofluorescence staining results demonstrated that the cytoplasm of some of the injected BMSCs was red, indicating that the AKI conditions induced the renal-epithelial differentiation of the trapped BMSCs. HO-1 overexpression increased the renal-epithelial differentiation capacity of the BMSCs in vivo. The ratio of $\mathrm{CK}_{18}{ }^{+} \mathrm{DAPI}^{+}$cells/DAPI ${ }^{+}$cells was higher in the HO-1-BMSCs group compared with the BMSCs and the eGFP-BMSCs groups ( $\mathrm{P}<0.05$; Fig. 6).

HO-1 overexpression improves the treatment effect of BMSCs on $I / R-A K I$. A previous study by the present research team demonstrated that the administration of BMSCs was able to improve the renal function of rats with I/R-AKI. Furthermore, rats treated with HO-1-BMSCs exhibited significantly lower levels of blood urea nitrogen (BUN) and serum creatinine 
A

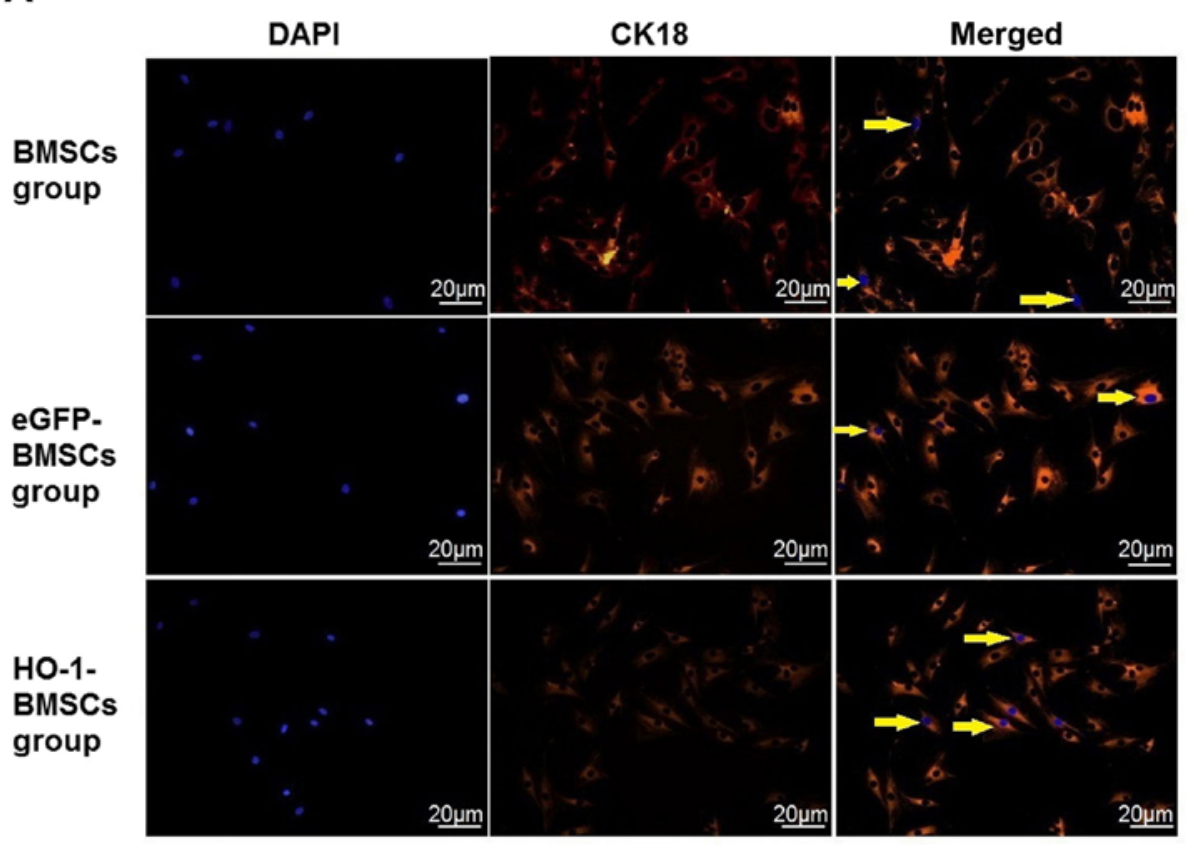

B

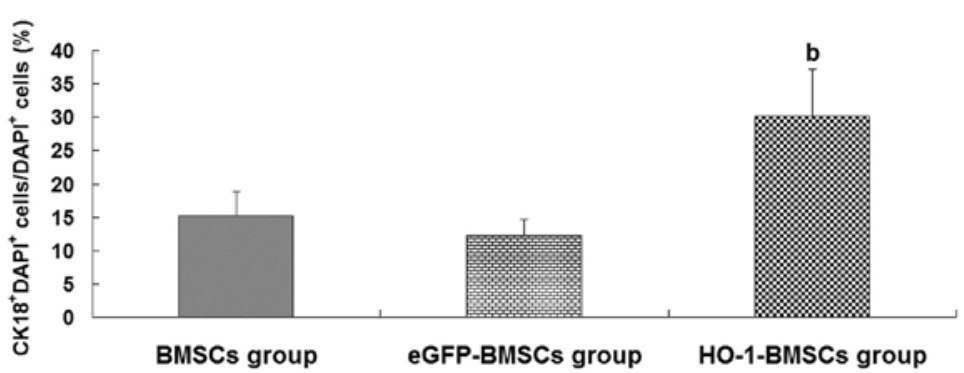

Figure 6. CK18 ${ }^{+}$BMSCs trapped in the kidneys of rats with ischemia/reperfusion-induced acute kidney injury. (A) Immunofluorescent staining images. Some implanted BMSCs stained positively for CK18, indicating the renal-epithelial differentiation of BMSCs. Blue nuclei in the left panel indicate DAPI ${ }^{+}$cells (BMSCs) red cytoplasms in the middle panel indicate $\mathrm{CK} 18^{+}$cells, and arrows in the right panel (blue nuclei with red cytoplasms) indicate $\mathrm{CK} 18^{+} \mathrm{DAPI}{ }^{+}$cells $\left(\mathrm{CK} 18^{+} \mathrm{BMSCs}\right)$. Scale bar, $20 \mu \mathrm{m}$. (B) Quantitative analysis. HO-1 gene modification increased the renal-epithelial differentiation capacity of BMSCs, and the ratio of CK18 $\mathrm{BMSCs} / \mathrm{BMSCs}$ in the HO-1-BMSCs group was the highest. Results are presented as the mean \pm standard deviation ( $\mathrm{n}=10 \mathrm{rats}){ }^{\mathrm{b}} \mathrm{P}<0.05 \mathrm{vs}$. BMSCs group. CK18, cytokeratin 18; BMSCs, bone marrow-derived mesenchymal stem cells; HO-1, heme oxygenase-1; eGFP, enhanced green fluorescent protein.

A

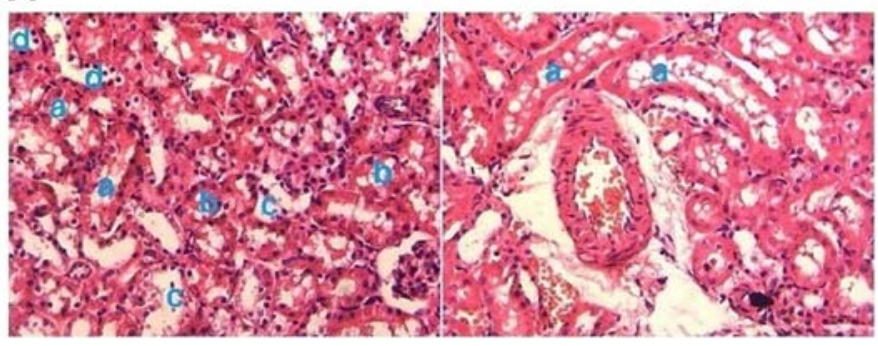

Model group
B

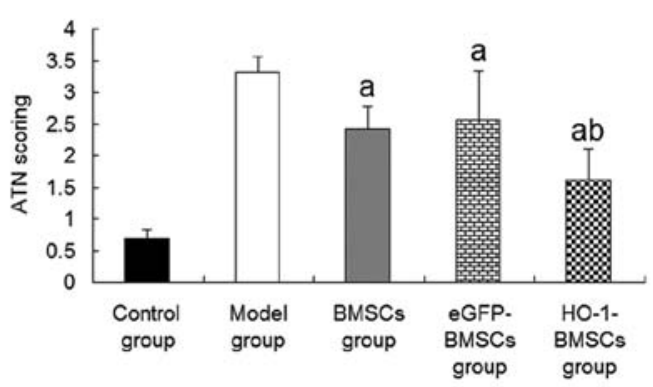

Figure 7. Therapeutic efficacy of HO-1-BMSCs in rats with ischemia/reperfusion-induced acute kidney injury. (A) Pathological images of periodic acid-Schiff staining in the model group (x200 magnification). The model group exhibited severe renal tubular necrosis. The blue letters indicate the following features: a, rush border loss; b, vacuolar degeneration; c, epithelial cells sloughed off into the tubular lumen; and d, regenerated tubular cells. (B) ATN scores. BMSC implantation decreased the ATN score, with the lowest score in the HO-1-BMSCs group. Results are presented as the mean \pm standard deviation (n=10 rats). ${ }^{a} \mathrm{P}<0.05$ vs. model group; ${ }^{\mathrm{b}} \mathrm{P}<0.05$ vs. BMSCs group. HO-1, heme oxygenase-1; BMSCs, bone marrow-derived mesenchymal stem cells; ATN, acute tubular necrosis; eGFP, enhanced green fluorescent protein.

(Scr) than rats treated with unmodified BMSCs (24). To further substantiate these results, histological examinations of the tubular tissues were conducted and ATN scores were evaluated. In the model group, PAS staining (Fig. 7A) revealed 
that some tubules displayed brush border loss, vacuolar degeneration and the sloughing off of epithelial cells into the tubular lumen. The ATN score was high. In comparison with the model group, the rats treated with BMSCs or eGFP-BMSCs exhibited significantly reduced ATN scores compared with the model group $(\mathrm{P}<0.05 ;$ Fig. $7 \mathrm{~B})$. The reduction of the ATN score in the HO-1-BMSCs-treated rats was significantly greater than those of the rats in the BMSCs group $(\mathrm{P}<0.05$; Fig. $7 \mathrm{~B})$.

\section{Discussion}

BMSCs transplantation has been proposed to repair AKI via differentiation into renal cells or by the paracrine effect (33-36). However, the therapeutic efficacy has been hindered by the death and low nephrogenic-differentiation of those cells when they are implanted in vivo. Previous studies have revealed the adverse effect of ROS on the survival and differentiation of the implanted BMSCs trapped in the I/R-AKI kidney (24). These toxic ROS are generated in the ischemia tissue following reperfusion (37). Thus, reducing the level of ROS may be an appealing approach to improve the outcome of the implanted BMSCs and subsequently obtain a better therapeutic effect.

HO-1, which was initially identified as the rate-limiting enzyme in the degradative pathway of heme, is now recognized to have cytoprotective effects (38). HO-1 and its byproducts (iron, carbon monoxide and biliverdin), possess the potential ability to eliminate the elevated ROS levels and thereby prevent cells from programmed cell death in the ischemic environment $(18,39,40)$.

As mentioned above, $\mathrm{HO}-1$ expression in BMSCs is induced by many stress mediators, but in limited amounts that are not able to counteract the injury caused by the stress, or exert a positive effect. Therefore, in the present study, the overexpression of HO-1 in BMSCs was achieved via gene transfection. In a previous study conducted using these cells, it was demonstrated that the levels of superoxide dismutase and glutathione peroxidase were significantly increased in HO-1-BMSCs/AKI-KHS compared with BMSCs/AKI-KHS (24). This suggests that the ROS level in HO-1-BMSCs may be substantially decreased, and that the enhanced HO-1 expression may have a potentially positive effect of on the survival and differentiation of BMSCs in the AKI microenvironment.

The results of experiments performed in the present study confirmed this hypothesis. Following treatment with AKI-KHS, the proportion of HO-1-BMSCs at the G0/G1 phase was decreased and the proportion of $\mathrm{PCNA}^{+} \mathrm{HO}-1-\mathrm{BMSCs}$ was increased significantly compared with those in the control BMSCs. In agreement with observations from the in vitro experiment, the in vivo experiment also revealed a significantly elevated $\mathrm{PCNA}^{+} \mathrm{DAPI}^{+} / \mathrm{DAPI}^{+}$cell ratio in the HO-1-BMSCs group.

The effect of implanted BMSCs on AKI repair is partly due to their direct nephrogenic differentiation process $(33,34)$. The effect of HO-1 overexpression on the nephrogenic differentiation of BMSCs was also tested in the present study. BMSCs indirectly cultured with AKI-KHS were used to imitate implanted BMSCs trapped in the injured kidney in vivo. Higher numbers of organelles were observed in the cytoplasm of the BMSCs in the BMSCs/AKI-KHS group. In addition, microvilli and intercellular junctions that are specific to epithelial cells were also visible on the surface of the BMSCs. These phenomena suggest the renal-epithelial differentiation of BMSCs. These ultrastructural changes were also observed in the HO-1-BMSCs/AKI-KHS group. CK18, a specific marker of renal tubular epithelial cells, was also tested in the present study. $\mathrm{CK} 18^{+}$BMSCs were observed in the BMSCs/AKI-KHS group, the eGFP-BMSCs/AKI-KHS group and the HO-1-BMSCs/AKI-KHS group, but the highest proportion of $\mathrm{CK} 18^{+} \mathrm{BMSCs}$ was detected in the HO-1-BMSCs/AKI-KHS group. Consistent with this, the highest proportion of $\mathrm{CK} 18^{+} \mathrm{BMSCs}$ was observed in the HO-1-BMSCs group in the I/R-AKI kidney in vivo.

The improved BMSC survival and increased renal-epithelial differentiation observed in the in vivo experiment induced a great improvement of the renal function in the AKI rats, including low BUN and Scr levels (24). In addition, a significantly reduced ATN score was observed in the HO-1-BMSCs group compared with the BMSCs group.

In the present study, the downstream signaling pathways involved in the cytoprotective effect of HO-1 overexpression were explored. The PI3K/Akt and MEK/ERK pathways are the most prominent survival signaling cascades that are stimulated in different cell types (41-44). Previous studies suggest that signaling through the PI3K pathway leads to the phosphorylation of $\mathrm{Akt}$, which in turn serves a pivotal role in the regulation of survival in BMSCs $(32,45)$. In addition, it has been documented that the activation of MEK/ERK mediates the survival of BMSCs (45). Other studies have demonstrated that the Akt and ERK signaling pathways are involved in the differentiation ability of BMSCs $(31,32)$. In the in vitro experiment in the present study, western blot analysis revealed that the levels of pAkt and pERK were the highest in the HO-1-BMSCs. Proliferation and differentiation assays using a PI3K-specific inhibitor (LY294002) and MEK inhibitor (PD98059) demonstrated that each of these inhibitors significantly decreased the proportions of $\mathrm{PCNA}^{+}$cells and $\mathrm{CK} 18^{+}$cells in the HO-1-BMSCs. Therefore, it is likely that the PI3K/Akt and MEK/ERK signaling pathways are involved in the improved survival and renal-epithelial differentiation of BMSCs induced by the HO-1 overexpression in the AKI microenvironment.

In conclusion, the present study indicates that overexpression of HO-1 in BMSCs enhances the survival and the renal-epithelial differentiation of BMSCs in the AKI microenvironment. Stimulation of PI3K/Akt and MEK/ERK signaling pathways may be the mechanism underlying the effects of HO01. When BMSC transplantation was used as a treatment for AKI in the rat model, the use of HO-1-BMSCs was associated with an improved renal function and reduced ATN score.

\section{Acknowledgements}

Not applicable.

\section{Funding}

The authors acknowledge financial support from Shanghai Key Projects of Basic Research (grant no. 12DJ1400203), National Natural Science Foundation of China (grant no. 81300568), Medical Youth Training Project of PLA (grant no. 13QNP050), 
Training Programme Foundation for Young Talents in Shanghai City Health System (grant no. XYQ2013088) and Specific Project of Nanjing Military Command (grant no. ZX07).

\section{Availability of data and materials}

All data generated or analysed during this study are included in this published article.

\section{Authors' contributions}

NL conceived the study, drafted and revised the manuscript. NL, HW and GH conceived the study. HW and GH participated in the design of the study. JC, WH and JZ performed the statistical analysis and the experiments. All authors read and approved the final manuscript.

\section{Ethics approval and consent to participate}

Ethical approval for the study was provided by the Animal Experimentation Institution of the Second Military University (Shanghai, China).

\section{Consent for publication}

Not applicable.

\section{Competing interests}

The authors confirm that they have no competing interests.

\section{References}

1. Lameire N, Van Biesen W and Vanholder R: The changing epidemiology of acute renal failure. Nat Clin Pract Nephrol 2 . 364-377, 2006

2. Oeyen S, Vandijck D, Benoit D, Decruyenaere J, Annemans L and Hoste E: Long-term outcome after acute kidney injury in critically-ill patients. Acta Clin Belg 62 (Suppl 2): 337-340, 2007.

3. Ulusoy S, Ar1 D, Ozkan G, Cansiz Mand Kaynar K: The frequency and outcome of acute kidney injury in a tertiary hospital: which factors affect mortality? Artif Organs 39: 597-606, 2015.

4. Morigi M, Introna $M$, Imberti $B$, Corna $D$, Abbate $M$, Rota $C$ Rottoli D, Benigni A,Perico N,Zoja C, et al: Human bone marrow mesenchymal stem cells accelerate recovery of acute renal injury and prolong survival in mice. Stem Cells 26: 2075-2082, 2008.

5. Herrera MB, Bussolati B, Bruno S, Fonsato V, Romanazzi GM and Camussi G: Mesenchymal stem cells contribute to the renal repair of acute tubular epithelial injury. Int J Mol Med 14: $1035-1041,2004$

6. Tögel F, Hu Z, Weiss $\mathrm{K}$, Isaac J, Lange $\mathrm{C}$ and Westenfelder C: Administered mesenchymal stem cells protect against ischemic acute renal failure through differentiation-independen mechanisms. Am J Physiol Renal Physiol 289: F31-F42, 2005.

7. Lange $C$, Tögel F, Ittrich $H$, Clayton F, Nolte-Ernsting C, Zander AR and Westenfelder C: Administered mesenchymal stem cells enhance recovery from ischemia/reperfusion-induced acute renal failure in rats. Kidney Int 68: 1613-1617, 2005.

8. Sadek EM, Afifi NM, Elfattah LI and Mohsen MA: Histological study on effect of mesenchymal stem cell therapy on experimental renal injury induced by ischemia/reperfusion in male albino rat. Int J Stem Cells 6: 55-66, 2013.

9. Liu N, Tian J, Wang W, Cheng J, Hu D and Zhang J: Effect and mechanism of erythropoietin on mesenchymal stem cell proliferation in vitro under the acute kidney injury microenvironment. Exp Biol Med (Maywood) 236: 1093-1099, 2011.

10. Frippiat C, Dewelle J, Remacle J and Toussaint O: Signal transduction in $\mathrm{H}_{2} \mathrm{O}_{2}$-induced senescence-like phenotype in human diploid fibroblasts. Free Radic Biol Med 33: 1334-1346, 2002.
11. Wei H, Li Z, Hu S, Chen X and Cong X: Apoptosis of mesenchymal stem cells induced by hydrogen peroxide concerns both endoplasmic reticulum stress and mitochondrial death pathway through regulation of caspases, p38 and JNK. J Cell Biochem 111: 967-978, 2010.

12. Mimeault M and Batra SK: Recent insights into the molecular mechanisms involved in aging and the malignant transformation of adult stem/progenitor cells and their therapeutic implications. Ageing Res Rev 8: 94-112, 2009.

13. Yang Y, Yang D, Yang D, Jia R and Ding G: Role of reactive oxygen species-mediated endoplasmic reticulum stress in contrast-induced renal tubular cell apoptosis. Nephron Exp Nephrol 128: 30-36, 2014

14. Hoffmann J, Glassford AJ, Doyle TC, Robbins RC, Schrepfer S and Pelletier MP: Angiogenic effects despite limited cell survival of bone marrow-derived mesenchymal stem cells under ischemia. Thorac Cardiovasc Surg 58: 136-142, 2010.

15. Zhang YG, Yang Z, Zhang H, Wang C, Liu M, Guo X and Xu P: Effect of negative pressure on human bone marrow mesenchymal stem cells in vitro. Connect Tissue Res 51: 14-21, 2010.

16. Barbagallo I, Tibullo D, Di Rosa M, Giallongo C, Palumbo GA, Raciti G, Campisi A, Vanella A, Green CJ and Motterlini R: A cytoprotective role for the heme oxygenase-1/CO pathway during neural differentiation of human mesenchymal stem cells. J Neurosci Res 86: 1927-1935, 2008.

17. Otterbein LE, Bach FH, Alam J, Soares M, Tao Lu H, Wysk M, Davis RJ, Flavell RA and Choi AM: Carbon monoxide has anti-inflammatory effects involving the mitogen-activated protein kinase pathway. Nat Med 6: 422-428, 2000.

18. Melo LG, Agrawal R, Zhang L, Rezvani M, Mangi AA, Ehsan A, Griese DP, Dell'Acqua G, Mann MJ, Oyama J, et al: Gene therapy strategy for long-term myocardial protection using adeno-associated virus-mediated delivery of heme oxygenase gene. Circulation 105: 602-607, 2002.

19. Yet SF, Perrella MA, Layne MD, Hsieh CM, Maemura K, Kobzik L, Wiesel P, Christou H, Kourembanas S and Lee ME: Hypoxia induces severe right ventricular dilatation and infarction in heme oxygenase-1 null mice. J Clin Invest 103: R23-R29, 1999.

20. Tang YL, Zhao Q, Qin X, Shen L, Cheng L, Ge J and Phillips MI: Paracrine action enhances the effects of autologous mesenchymal stem cell transplantation on vascular regeneration in rat model of myocardial infarction. Ann Thorac Surg 80: 229-236, 2005.

21. Zeng B, Ren X, Lin G, Zhu C, Chen H, Yin J, Jiang H, Yang B and Ding D: Paracrine action of HO-1-modified mesenchymal stem cells mediates cardiac protection and functional improvement. Cell Biol Int 32: 1256-1264, 2008

22. Hill-Kapturczak N, Chang SH and Agarwal A: Heme oxygenase and the kidney. DNA Cell Biol 21: 307-321, 2002.

23. Haugen EN, Croatt AJ and Nath KA: Angiotensin II induces renal oxidant stress in vivo and heme oxygenase-1 in vivo and in vitro. Kidney Int 58: 144-152, 2000.

24. Liu N, Wang H, Han G, Tian J, Hu W and Zhang J: Alleviation of apoptosis of bone marrow-derived mesenchymal stem cells in the acute injured kidney by heme oxygenase-1 gene modification. Int J Biochem Cell Biol 69: 85-94, 2015.

25. Nanmei L, Jun T, Jin C and Jinyuan Z: Migration of CXCR4 gene-modified bone marrow-derived mesenchymal stem cells to the acute injured kidney. J Cell Biochem 114: 2677-2689, 2013.

26. Oyama T, Watanabe H, Iwafuchi M, Maejima T and Ajioka Y: Diagnostic value of proliferating cell nuclear antigen for myogenic tumors of the stomach. Gartroenterol Jpn 28: 193-200, 1993.

27. Nakas-Ićindić E, Avdagić N, Mijanović M, Prasović S, Zaciragić A, Hadzović A and Tahirović G: Nitric oxide in gentamicin -induced acute tubular necrosis in rats. Bosn J Basic Med Sci 5: 70-74, 2005

28. Baer PC, Bereiter-Hahn J, Schubert R and Geiger H: Differentiation status of human renal proximal and distal tubular epithelial cells in vitro: differential expression of characteristic markers. Cells Tissues Organs 184: 16-22, 2006.

29. Colić M, Pejnović N, Kataranovski M, Stojanović N, Terzić T and Dujić A: Rat thymic epithelial cells in culture constitutively secrete IL-1 and IL-6. Int Immunol 3: 1165-1174, 1991.

30. Xu R, Chen J, Cong X, Hu S and Chen X: Lovastatin protects mesenchymal stem cells against hypoxia- and serum deprivation-induced apoptosis by activation of PI3K/Akt and ERK1/2. J Cell Biochem 103: 256-269, 2008.

31. Platt MO, Wilder CL, Wells A, Griffith LG and Lauffenburger DA: Multipathway kinase signatures of multipotent stromal cells are predictive for osteogenic differentiation: tissue-specific stem cells. Stem Cells 27: 2804-2814, 2009. 
32. Dai Z, Li Y, Quarles LD, Song T, Pan W, Zhou H and Xiao Z: Resveratrol enhances proliferation and osteoblastic differentiation in human mesenchymal stem cells via ER-dependent ERK1/2 activation. Phytomedicine 14: 806-814, 2007.

33. Li K, Han Q, Yan X, Liao L and Zhao RC: Not a process of simple vicariousness, the differentiation of human adipose-derived mesenchymal stem cells to renal tubular epithelial cells plays an important role in acute kidney injury repairing. Stem Cells Dev 19: 1267-1275, 2010.

34. Morigi M, Imberti B, Zoja C, Corna D, Tomasoni S, Abbate M, Rottoli D, Angioletti S, Benigni A, Perico N, et al: Mesenchymal stem cells are renotropic, helping to repair the kidney and improve function in acute renal failure. J Am Soc Nephrol 15 : 1794-1804, 2004.

35. Tögel F, Weiss K, Yang Y, Hu Z, Zhang P and Westenfelder C: Vasculotropic, paracrine actions of infused mesenchymal stem cells are important to the recovery from acute kidney injury. Am J Physiol Renal Physiol 292: F1626-F1635, 2007.

36. Semedo P, Wang PM, Andreucci TH, Cenedeze MA, Teixeira VP, Reis MA, Pacheco-Silva A and Câmara NO: Mesenchymal stem cells ameliorate tissue damages triggered by renal ischemia and reperfusion injury. Transplant Proc 39: 421-423, 2007.

37. Haugen $E$ and Nath KA: The involvement of oxidative stress in the progression of renal injury. Blood Purif 17: 58-65, 1999.

38. Courtney AE and Maxwell AP: Heme oxygenase 1: does it have a role in renal cytoprotection? Am J Kidney Dis 51: 678-690, 2008.

39. Vulapalli SR, Chen Z, Chua BHL, Wang T and Liang CS: Cardioselective overexpression of HO-1 prevents I/R-induced cardiac dysfunction and apoptosis. Am J Physiol Heart Circ Physiol 283: H688-H694, 2002.
40. Ozaki KS, Yoshida J, Ueki S, Pettigrew GL, Ghonem N, Sico RM, Lee LY, Shapiro R, Lakkis FG, Pacheco-Silva A, et al: Carbon monoxide inhibits apoptosis during cold storage and protects kidney grafts donated after cardiac death. Transpl Int 25: 107-117, 2012.

41. Gonzalez-Zulueta M, Feldman AB, Klesse LJ, Kalb RG, Dillman JF, Parada LF, Dawson TM and Dawson VL: Requirement for nitric oxide activation of p21(ras)/extracellular regulated kinase in neuronal ischemic preconditioning. Proc Natl Acad Sci USA 97: 436-441, 2000.

42. Brunet A, Datta SR and Greenberg ME: Transcription-dependent and -independent control of neuronal survival by the PI3K-Akt signaling pathway. Curr Opin Neurobiol 11: 297-305, 2001

43. Downward J: PI 3-kinase, Akt and cell survival. Semin Cell Dev Biol 15: 177-182, 2004.

44. Di Santo S, Seiler S, Fuchs AL, Staudigl J and Widmer HR: The secretome of endothelial progenitor cells promotes brain endothelial cell activity through PI3-kinase and MAP-kinase. PLoS One 9: e95731, 2014.

45. Isele NB, Lee HS, Landshamer S, Straube A, Padovan CS, Plesnila $\mathrm{N}$ and Culmsee C: Bone marrow stromal cells mediate protection through stimulation of PI3-K/Akt and MAPK signaling in neurons. Neurochem Int 50: 243-250, 2007.

This work is licensed under a Creative Commons Attribution-NonCommercial-NoDerivatives 4.0 International (CC BY-NC-ND 4.0) License. 